\title{
DAS FORMAÇÕES QUE PRECEDERAM O CAPITALISMO AO MODO DE PRODUÇÃO VIGENTE: CONTRIBUIÇÕES PARA REFLETIR A RELAÇÃO SER HUMANO - NATUREZA
}

Darlene Silveira Cabrera ${ }^{1}$ Luis Fernando Minasi ${ }^{2}$ Alex Nunes Molina ${ }^{3}$

\begin{abstract}
RESUMO
O presenteartigo foi sistematizado a partir de algumas das obras de Karl Marx (2010; 2011; 2012; 2017), em especial a obra Grundrisse, tendo como objetivo discutir e compreender como se organizaram algumas formações sociais - ao longo da história da humanidade - que precederam o atual modo de produção capitalista, bem como entender como esse movimento histórico contribuiu para configurar a relação ser humano - natureza. Para tanto, o trabalho compila os resultados de uma pesquisa de cunho qualitativo, que laçou mão da metodologia de revisão bibliográfica e, teve, também, como subsídio as pesquisas realizadas por alguns interlocutores de Marx como Mèszàros (2008; 2011; 2012; 2015); Santos (2014); Foladori (2001).

Palavras- chave: Formações pré-capitalistas; Modo de produção vigente;KarlMarx;Relação ser humano - natureza
\end{abstract}

\section{OF FORMATIONS THAT PRECEDED CAPITALISM IN THE MODE OF CURRENT PRODUCTION: CONTRIBUTIONS TO REFLECT THE RELATIONSHIP BEING HUMAN - NATURE}

\begin{abstract}
This article was systematized from some of the works of Karl Marx (2010, 2011, $2012,2017)$, in particular Grundrisse, in order to discuss and understand how some social formations - throughout human history - which preceded the present capitalist mode of production, as well as to understand how this historical movement contributed to the configuration of the human-nature relationship. In order to do so, the paper compiles the results of a qualitative research, which used the methodology of bibliographic revision and also had as a subsidy the researches carried out by some of Marx's interlocutors such as Mészàros (2008, 2011, 2012, 2015) ; Santos (2014); Foladori (2001).

Keywords: Pre-capitalist formations; Mode of production in force;Karl Marx; Relationship human being - nature

\footnotetext{
1 Doutoranda do Programa de Pós-Graduação em Educação Ambiental da Universidade Federal do Rio Grande.

${ }^{2}$ Docente do Programa de Pós-Graduação em Educação Ambientala (PPGEA/FURG).

${ }^{3}$ Mestrando do Programa de Pós-Graduação em Educação Ambiental da Universidade Federal do Rio Grande.
} 


\section{INTRODUÇÃO}

Sistematizamos o presente artigo intencionando discutir e compreender como algumas das formas de organização das sociedades - ao longo da história da humanidade - precederam o atual modo de produção capitalista, bem como contribuíram para segregar a relação ser humano - natureza natural no movimento histórico que configurou o modelo econômico vigente.

As análises que realizamos sobre tais organizações sociais, as quais pressupõe uma divisão didática em três grandes blocos e é encerrada, nesse momento histórico, no quarto bloco:o modo de produção capitalista, são subsidiadas pelo pensamento do filosofo $\operatorname{Karl} \operatorname{Marx}(2010$; 2012; 2017), primordialmente nos escritos desse autor postumamente publicados como Grundrisse (2011). Tal análise se configurou tendo como premissa as condições objetivas de reprodução e manutenção da sociabilidade humana, sela ela pela apropriação da condição natural do trabalho ou pela relação do comportamento territorial, e suas guerras seculares, como propriedade do indivíduo trabalhador.

Ademais, as formas de organizações sociais que discutimos engendram as formasde reprodução das relações sociais dos indivíduos aliadas a maneira como organizavam a economia. Sendo, assim exaltamos a centralidade da economia dessas formações sociais como perpetuadora das comunidades, pelo viés da produção da riqueza material e da manutenção da propriedade privada.

Nesse sentido, compreendemos que essas organizações sociais - as quais estamos concebendo como Formações que precederam o capitalismo, fundamentados nas análises de Karl Marx (2010) - não se desenvolveram na materialidade do mundo de forma linear, mas coexistiram isoladamente a partir das condições materiais: meio físico natural e meio cultural, em diferentes lugares. Relações essas, que somente se originaram de forma isolada, devido à inexistência dos meios tecnico-cientifico-informacional ${ }^{4}$ capaz de prover a

\footnotetext{
${ }^{4} \mathrm{O}$ conceito de meio técnico-cientifico-informacional cunhado pelo geografo brasileiro marxista Milton Santos (1994) refere-se ao "meio geográfico onde o território inclui obrigatoriamente ciência, tecnologia e informação. [...] é a nova cara do espaço e do tempo.É aí que se instalam
} 
comunicação entre elas, questão que não poderia ocorrer após a efetivação do modo de produção capitalista e o advento da globalização (SANTOS, 2014).

Para tanto, buscamos compreender como as diferentes Formações que precederam o capitalismo se organizaram enquanto processo até o momento em que culminam na Revolução Industrial, no desenvolvimento tecnológico e informacional - o qual se configura como metabolismo do capital (MÉSZÁROS, 2011).

Embasados, então, nas análises e apontamentos sistematizados por Karl Marx (2011), pincipalmente nos alfarrábios compilados na obra Grundrisse, almejamos discutir nesse estudo bibliográfico como tais organizações sociais contribuíram, para que em determinado momento histórico, culminasse no desenvolvimento do sistema capitalista e na separação do ser humano da natureza natural.

Destarte, Karl Marx direciona suas análises na perspectiva de abordar como se desenvolvia a economia de tais comunidades, assim a partir das aproximações do modus de produção dessas comunidades, Marx (2011) as distinguiu em quatro principais grupos. Portanto, partiremos desse fundamento para discutir e buscar entender como tais organizações sociais se desenvolveram até culminarem no sistema capitalista.

Em suma, concebemos que o processo histórico pelo qual foram constituídas as diferentes organizações sociais não desaparece, pois segundo Marx (2011), cada uma delas aparece em uma relação negativa com a outra, viabilizando de um lado o trabalhador livre potencialmente e do outro as relações sociais que formam o capital. De modo que, resulta na cisão da unidade entre as condições materiais objetivas e a organização de classe, para a manutenção do modo de produção vigente, deixando no lugar o que concebemos hoje como trabalho livre.

\section{O DESENVOLVIMENTO DAS FORMAÇÕES SOCIAIS QUE PRECEDERAM O CAPITALISMO: O MOVIMENTO DA RELAÇÃO SER HUMANO - NATUREZA.}

as atividades hegemônicas, aquelas que têm relações mais longínquas e participam do comércio internacional, fazendo com que determinados lugares se tornem mundiais." 
Temos como centralidade, nesse texto, discutir e refletir sobre asformações sociais que precedem o modo de produção capitalista e como os seres humanos nessas se relacionavam com a natureza natural, tendo como subsídio o pensamento de Karl Marx. Contudo, destacamosnossa intenção deorganizar didaticamente as compreensões de Marx (2011) sobre tais formações, as quais foram discutidas pelo autorsem um polimento da escrita, com ideias ainda incompletas e em muitos momentos confusas - enquanto rascunho.

Desde já, ressaltamos, que a sistematizamos as formações que precedem o capitalismo não no sentido de engessar ou desconsiderar o movimento dinâmico da história da humanidade. Isto é, estamos considerando a ideia de não linearidade histórica das organizações sociais apontadas por Marx (2011), tanto na totalidade das obras do autor, quanto nos rascunhos hoje editados como o livro: Grundrisse.

Ponderamos, ainda, que tais comunidades discutidas enquanto formações que precedem o modo econômico vigente se desenvolveram concomitantemente e de forma mais isolada devido à precariedade dos meios de comunicação da época, os quais poderiam ser limitantes da não conexão entre essas organizações sociais. Consideramos, assim, que 0 desenvolvimento dos meios técnicos informacionais contribuiu significativamente para o processo de aproximação, dominação e padronização das múltiplas comunidades nos mais longínquos lugares do mundo (SANTOS, 2014) - questão que influenciou diretamente o acelerado processo da disseminação do capitalismo.

Nesse sentido, partimos das reflexões de Karl Marx (2010; 2011; 2012; 2017) para compreendermos o que possibilitou o avanço das formações precedentes ao capitalismo até culminarem no modo de produção vigente avanços os quais contribuíram para a segregação do ser humano da natureza natural. Estamos entendendo, portanto, que há uma importante ruptura social que precisa ser manifestada quando do advento da separação dos seres humanos - dos trabalhadores - de seu laboratório natural: a terra. 
Destacamos a terra como a base fundamental para tais comunidades, sendo essa: a base sede da comunidade, a matéria prima e o meio de produção ${ }^{5}$ para reprodução da existência dos sujeitos desse lugar. Essa desvinculação do ser humano do meio de produção inviabiliza mulheres e homens de se relacionarem com as condições objetivas de seu trabalho: a natureza natural enquanto propriedade coletiva.

Atrelada à sistematização do primeiro grande grupo de formação pré capitalista Marx (2011) saliente que a desvinculação do trabalhador do meio de produção é basilar para compreendermos como ocorreu a dissolução da pequena propriedade livre de terras, como é o caso da propriedade comunitária baseada na comunidade oriental (MARX, 2011).

Nessa forma, pois, de organização social, os seres humanos compreendem os meios de produção como sua propriedade, assim constituindo uma unidade natural entre 0 trabalho e seus pressupostos objetivos, propiciando ao trabalhador por meio do trabalho uma existência objetiva:

\begin{abstract}
O indivíduo relaciona-se consigo mesmo como proprietário, como senhor das condições de sua realidade. Ele se relaciona da mesma maneira com os outros [...] como coproprietários, como tantas encarnações da propriedade comum, ou como proprietários independentes existindo junto com ele - entre os quais a própria propriedade comum, que outrora a tudo absorvia e a todos abrangia, é posta como agerpublicus particular junto aos muitos proprietários privados de terras (MARX, 2011, p.627-628).
\end{abstract}

Nesse constructo social, as mulheres e homens não se compreendem como trabalhadores, mas como proprietários, sujeitos que são parte de uma comunidade e que trabalham nela (MARX, 2011). Assim, o objetivo final dessa forma de trabalho, na especificidade dessa comunidade, não é criação de valor- mesmo que se realize o trabalho excedente para trocá-lo por trabalho alheio - e sim a conservação do proprietário singular e de sua família, bem como a manutenção da comunidade enquanto totalidade.

\footnotetext{
${ }^{5}$ Terminologia utilizada por Marx em o Capital, livro I, de 2013 para designar os meios usados pelos homens para produção dos bens necessários à reprodução material da vida humana e da sociedade como um todo.
} 
Por conseguinte, carreamos para nossa explanação, acerca das concepções de Karl Marx (2011), sobre os diferentes modos de organização social, partimos das coletividades tribais, originadas no gregarismo ${ }^{6}$,cuja formação se dá pela formação da família e ampliação no clã, ou pelo casamento entre indivíduos do mesmo clã, ou até pela inter-relação de clãs.

Esse tipo de formações iniciais [coletividades tribais] apresentavam marcantes relações com a natureza, tinham uma vida pastoril e migratória, mantendo-se por tempo maior em regiões mais férteis de recursos naturais, organizavam-se no sentido de apropriação temporária e utilização coletiva do solo. Contudo, no momento em que se fixavam, acabavam sofrendo influências de condições exteriores aos clãs: clima, condições geográficas e sociais (disputa entre clãs), assim modificando suas características coletivas originárias (MARX, 2011).

Para tais comunidades, cada um dos seus indivíduos é proprietário do montante produzido pelo trabalho coletivo, no entanto aapropriação real pelo processo do trabalho se realiza sob determinadospressupostos, os quais são considerados por Marx (2011) divinos ou naturais.

No cerne dessa forma primária de organização encontramos também a formação asiática, cuja tem sua centralidade na figura do proprietário supremo. Logo, a organização se dá na centralidade de umaunidade suprema, a qual aglutina todas as pequenas propriedades em uma única unidade coletiva.

Conforme esclarece Marx (2011):

[...] namaioria das formas asiáticas fundamentais, a unidadecoletiva que se situa acima de todas essas pequenascomunidades apareça como o proprietário supremo ou oúnico proprietário, ao passo que as comunidades reaisapareçam apenas como possuidoras hereditárias. Sendo aunidade o proprietário real e o pressuposto real da propriedadecomunitária, essa própria unidade pode aparecercomo um particular acima das numerosas comunidadesparticulares reais, em que o indivíduo singular é então de fato privado de propriedade, ou em que a propriedade -a atitude do indivíduo em relação às condições naturaisdo trabalho e da reprodução como pertencendo a

\footnotetext{
${ }^{6}$ Segundo Marx (2011) esse é o primeiro pressuposto de organização da apropriação das condições objetivas da coletividade tribal, e, da atividade que a reproduz e objetiva: comunidade de sangue, linguagem costumes, etc.
} 
ele, comoo corpo objetivo, natureza inorgânica dada, de suasubjetividade - aparece-lhe mediada pela supressão daunidade geral, que é realizada no déspota como o pai dasmuitas comunidades, e no indivíduo singular, pela mediaçãoda comunidade particular. Com isso, o produto excedente- que, aliás, é determinado legalmente em razãoda apropriação real pelo trabalho - pertence por si só aessa unidade suprema. (MARX, 2011, p. 629 - 630).

Mediante a análise do autor, essas formações sociais [formações asiáticas] engendram um caráter centralizador de poder instituído pela hereditariedade, configurando-se na supressão da unidade geral e a centralização no déspota ${ }^{7}$. Essa figura pode, igualmente, ser caracterizada pelo poder divino a ela acrescido por ter descendido dos déspotas que a antecederam.

Não obstante, o modo de produção asiático é gerado da combinação entre manufatura e agricultura (MARX, 2011). E o resultante dos trabalhos desenvolvidos - o excedente - pertence a "coletividade mais elevada" existente, a qual se manifesta na forma de pessoa [o déspota]. Assim, o excedente pode ser destinado ao déspota como glorificação a sua competência real ou divina, ou entregue como tributo.

Essas comunidades, segundo Marx (2011), podem ser compreendidas como uma propriedade comunitária, onde os indivíduos desenvolvem seu trabalho de modo autônomo com sua família, na extensão de terra que lhes foi designada (desde que o excedente seja produzido e chegue ao déspota em forma de agrado ou tributo). Nesse interstício, podemos compreender, a partir do autor, o surgimento de um dominiunsenhorial - como é o caso das comunidades eslavas e romenas - sendo possível vislumbrarmos indícios da servidão.

Dentre essas comunidades - as quais Marx (2011) organiza, ainda, no cerne de uma primeira forma de desenvolvimento pré-capitalista - estão às unidades que podem ser concebidas como um sistema formal coletivo, onde o

\footnotetext{
${ }^{7}$ Marx (2011, p. 630) corrobora com uma melhor compreensão a respeito dessa figura despótica quando coloca que "Uma parte do trabalho excedente pertence à coletividade mais elevada que existe finalmente como pessoa;trabalho excedente este que se manifesta seja no tributo etc., seja no trabalho coletivo para a glorificação da unidade, em parte do déspota real, em parte do ente imaginário do clã, do deus."
} 
trabalho é desenvolvido coletivamente entre toda a comunidade. Assim, tal caráter coletivo pode vir a se manifestar no interior de um sistema tribal, sendo ordenado tanto por um chefe de família tribal, quanto pela relação recíproca entre os patriarcas de duas famílias.

O desenvolvimento dessas comunidades, calcadas então no trabalho usurpado de alguns indivíduos que as compõem - criam condições de, em seus arredores, propiciarem a constituição das cidades. Essas cidades se organizam ao lado dos povoados, enquanto "pontos especialmente favoráveis ao comércioexterior; ou onde o chefe de Estado e seus sátrapastrocavam sua renda (produto excedente) por trabalho,gastando-a como fundo de trabalho." (MARX, 2011, p. 631).

Ao perseguirmos nosso objetivo de sistematizar para melhor compreender as "Formações sociais que precedem o modo de produção capitalista", iniciamos a discussão sobre o segundo bloco das formações que precedem o capitalismo. Nesse caso, o campo aparece como território da cidade, assumindo assim o papel secundário, sendo a cidade constituída como sede de pessoas que provém da vida no campo.
A segunda forma - e ela, como a primeira, produziumodificações fundamentais em termos locais, históricosetc. -, produto de uma vida histórica mais movimentada[,das] vicissitudes e da modificação das tribos primitivas, presume também a comunidade como primeiro pressuposto,mas, à diferença do primeiro caso, não como substânciada qual os indivíduos são simples acidentes ou daqual eles constituem componentes puramente naturais; talforma não presume a terra como a base, mas a cidadecomo a sede já constituída das pessoas do campo. (Proprietáriosde terra.) 0 campo aparece como território da cidade;e não o povoado, como simples apêndice do campo. Aterra em si - por mais que possa oferecer obstáculos ao seucultivo, à sua apropriação efetiva - não oferece nenhumimpedimento para se relacionar com ela como a naturezainorgânica do indivíduo vivo, sua oficina de trabalho, seumeio de trabalho, objeto de trabalho e meio de vida dosujeito. As dificuldades encontradas pelo sistemacomunitário.(Marx, 2011, p. 631 , grifos nossos).

Essa segunda forma de organização se constitui em uma dinâmica histórica mais intensa em relação à primeira. No entanto, mesmo que traga como vicissitude das tribos iniciais a ideia de comunidade como centralidade, nessa forma de organização a relação com a terra - com a natureza natural não é presumida como a base da existência humana, mas sim as cidades. 
Para tanto, o trabalho no campo passa a ser preocupação secundária das organizações sociais, tendo em vista que parte significativa da terra já foi dominada, bem como o acúmulo de experiências sobre como se deve desenvolver o trabalho no campo. Logo, a preocupação eminente dos indivíduos se centra na formação das cidades, de mesmo modo que a atenção é voltada para a defesa dos territórios, pois aqueles que estão fora desses aglomerados buscam se inserir e se apropriar das mesmas condições de vida.

A guerra, então, surge desse movimento histórico como a grande tarefa conjunta para a perpetuação das ocupações territoriais. Assim, constituem - se as organizações familiares guerreiras - originando o sistema militar - cuja estratégia para proteção e defesa é concentrar os domicílios em locais próximos, ratificando a necessidade de constituição das cidades.

Desse modo, cada indivíduo tem, por si e para si, a necessidade de proteção mútua, permeando no espaço a defesa da propriedade comunitária como propriedade do Estado (agerpublicus). Porém, cabe a nós destacar, que a propriedade do indivíduo singular não é uma propriedade comunitária - ela é propriedade particular do indivíduo - qualificando-se assim a noção de propriedade privada. Não obstante, quanto mais o indivíduo se distancia do caráter comunitário, desenvolvendo outras condições de trabalho, mais distante fica do senso de coletividade.

Já a agricultura desenvolvida como meio de produção, de subsistência pelo proprietário enquanto trabalhador, tem a família (cônjuges e filhas) como partícipes das atividades do lugar. Porquanto, o trabalho é desenvolvido objetivando a sobrevivência e não o acúmulo de riqueza, mas sim a autoconservação como membro da comuna. Para tal, observamos que:

A continuidade da comuna é a reprodução de todos os seus membros
como camponeses autossuficientes, cujo tempo excedente pertence
justamente à comuna, ao serviço militar, etc. A propriedade sobre o
trabalho é mediada pela propriedade sobre a condição do
trabalho[...]. Não é pela cooperação no trabalho produtor de riqueza o
modo pelo qual o membro da comunidade se reproduz; mas
cooperação no trabalho para os interesses coletivos (imaginários e
reais) em vista da manutenção da associação externa e interna
(MARX, 2011, p.635).

Por outro lado, elucidamos a propriedade quiritária, ou seja, o proprietário privado de terra só pode sê-lo como romano, onde se expressam 
as relações entre patrícios e plebeus, bem como as relações exploratórias de "compensação" por parte dos primeiros frente aos trabalhadores (plebe), nesse ponto consolidando a transição para a servidão.

Por conseguinte, com o intuito de perseguir a compreensão sobre as "Formações sociais que precederam a produção capitalista", Karl Marx, no Grundrisse, fomenta nossa curiosidade sobre o desvelar de uma terceira forma de organização social. Pois, tal forma não dialoga com certos avanços apresentados em coerência entre as primeiras e as segundas formas précapitalistas.

Diante disso, Marx (2011) centra suas análises na propriedade dos indivíduos trabalhadores - os quais se organizam enquanto membros que se autossustentam na comunidade a partir das condições naturais de seu trabalho: a comunidade germânica. Nesse caso, o membro da comunidade não é copossuidor da propriedade coletiva, como é apresentado no caso das comunidades orientais, ou romanas e gregas, mas sim proprietário privado.

Além disso, na comunidade germânica, os indivíduos não se concentram nas cidades, organizando- se enquanto um coletivo que não é segregado em partes, como nas comunidades discutidas anteriormente:

Entre os germanos, onde os chefes de família individuais se fixamnas matas, separados uns dos outros por longas distâncias, a comunidade só existe, desde logo externamente considerada, pela reunião periódica dos membros da comunidade, se bem que sua unidade existente em si mesma está posta na descendência, na língua, no passado e história comuns etc (MARX, 2011, p.639).

Nessa organização social, a comunidade é constituída por sujeitos autônomos, proprietários de terra, dispostos em reunião e não em associação, não sendo subvencionada pelo Estado, como parte de um sistema estatal, pois aqui não existem os aglomerados urbanos - as cidades. Dessa maneira, a existência efetiva da comunidade dependia apenas das reuniões em assembleias, momento no qual os indivíduos que viviam distantes uns dos outros se reunião em prol da manutenção da existência de suas propriedades privadas familiares. 
Nesse sentido, Marx aponta que o agerpublicus das comunidades germânicas se constituía em prol das áreas comunitárias de caça, pastagem e extração de lenha:

\begin{abstract}
Entre os germanos, o agerpublicus aparece antes somente como complemento da propriedade individual e figura como propriedade somente na medida em que é defendido contra tribos inimigas como propriedade comunitária de uma tribo em particular.[...] No mundo antigo, a cidade com seu perímetro rural é a totalidade econômica; no mundo germânico, [é] cada residência individual, que, aparecendo ela própria só como um ponto na terra que lhe pertence, não é concentração de muitos proprietários, mas família como unidade autônoma (MARX, 2011, p. 640).
\end{abstract}

A terra segue, em todas as três formações até aqui discutidas, como condição objetiva de reprodução e manutenção da sociedade humana, seja pela apropriação da condição natural do trabalho, da terra, seja em relação ao comportamento territorial, e suas guerras, como propriedade do indivíduo trabalhador. Conforme corrobora Marx (2011, p. 643): “Um indivíduo isolado teria tão pouca possibilidade de ter propriedade de terra quanto de falar".

Em todas as formas de organizações sociais, por nós discutidas até então, a reprodução das relações sociais dos indivíduos atreladaa maneira como organizavam a economia é fundante, no sentido de perpetuação das comunidades, de produção da riqueza material e manutenção da propriedade privada.

Por conseguinte, Marx nos instiga a reflexão:

\begin{abstract}
Nunca encontramos entre os antigos uma investigação sobre qual forma de propriedade da terra é a mais produtiva, qual cria a maior riqueza. A riqueza não aparece como finalidade da produção[...]. A riqueza só aparece como fim em si mesma entre os poucos povos mercantis - monopolistas do comércio de carga - que vivem nos poros do mundo antigo, assim como os judeus na sociedade medieval (MARX, 2011, p.645).
\end{abstract}

Sob esse viés analítico o filosofo nos aponta para uma das categorias basilares da constituição da próxima formação social políticoeconômica - 0 sistema capitalista, o qual tem como fim a acumulação da riqueza. Essa organização social está centrada na "gênese extraeconômica da propriedade, a gênese histórica da economia burguesa" (MARX, 2011, p.47).

\title{
O MOdO DE PRODUÇÃO VIGENTE: O ESTADO MODERNO E A SEGREGAÇÃO DA RELAÇÃO SER HUMANO - NATUREZA.
}


A humanidade desenvolveu suas formas de sobrevivência em constante processo de mediação com a natureza, bem como aperfeiçoou seus modos de sociabilidade, passando a se concentrar em grupos cada vez maiores. Tal estratégia parece ter beneficiado a constituição das primeiras formas de sociedade e, com elas, o imperativo de atender as necessidades humanas primárias, como a fome, a moradia e o vestuário.

Não obstante, é no movimento de constituição da sociabilidade humana que o homem descobre o alimento como valor de uso e, desenvolve a economia voltada às necessidades advindas dessas formas produtivas em ascensão. Assim, consideramos que os diferentes modos de produção tornam propício o ambiente para a acumulação de bens para escambo e, na sequência desse processo, a geração de uma produção sistêmica de excedentes, que intensifica o comércio e acaba por determinar o processo de produção prioritariamente voltado para troca, momento esse que caracteriza as primeiras formas de relação entre capital e trabalho.

Para tanto, podemos observar que a acumulação dos bens gerados pelas diferentes formas de organizações pré-capitalistas foram apropriadas por determinado grupo social, o qual se tornou possuidor de grande parte da riqueza material. Tal grupo é o produto de um longo processo de desenvolvimento e transformações do modo de produção econômico e de seus meios de comunicação (SANTOS,2014).

Compreendemos, assim, esse grupo, a partir de Marx e Engels (2011), como os capitalistas modernos, proprietários dos meios de produção social e empregadores dos trabalhadores assalariados - a burguesia.

Desse modo, no processo de efetivação da produção sistêmica de excedentes, a burguesia imperativamente submete o campo à dominação das cidades, adensando o movimento de pessoas da área rural para a urbana e o aumento populacional nas cidades:

A burguesia controla cada vez mais a dispersão dos meios de produção, da propriedade e da população. Aglomerou a população, centralizou os meios de produção e concentrou a propriedade em poucas mãos. A consequência inevitável disso foi a centralização política. Províncias independentes, apenas federadas, com interesses, leis, governos, sistemas alfandegários diferentes, foram reunidas em uma só nação, em um só governo em um só código de 
lei, em um só interesse nacional de classe, em uma só fronteira alfandegária (MARX e ENGELS, 2011, p. 31).

Destarte, a burguesia moderna criou relações de produção de supremacia econômica e política capaz de dominar e de colocar a seu serviço a classe proletária. Classe essa, a qual não possui seus próprios meios de produção - e que para manter suas formas de sobrevivência se submete vendendo sua força de trabalho e seu tempo de vida à classe burguesa em troca de um salário (MARX e ENGELS, 2011).

Ademais, os proletários - trabalhadores assalariados - ao venderem sua força de trabalho, produzem um valor real maior que o custo do seu trabalho. Consequentemente, o valor extra, gerado pelo trabalhador é o excedente do trabalho, que não é dividido com quem o produziu, mas sim se torna propriedade do burguês - constituindo parte da "mais-valia" - que enquanto valor de troca constitui a riqueza da burguesia. Essa riqueza produzida pelo trabalhador é acumulada ao longo do tempo, gerando riqueza ao empregador em forma de capital.

Diante dessa organização econômica, a classe burguesa se depara frente à necessidade de criar meios para proteger sua riqueza e com ela o seu poder, e, para tanto, desenvolve diferentes instituições, que se ramificam e direcionam os interesses sociais: o Estado moderno, as milícias, a ciência, a religião e a arte (BRANDÃO, 2006).

Conforme nos enfatiza Lenin (1987, p. 55), O Estado se constitui“no lugar, na hora e no grau em que as condições de classe não podem, objetivamente, conciliar-se. E vice-versa: a existência do Estado demonstra que as contradições de classe são inconciliáveis.".

Desse modo, o Estado vislumbrando conciliares as eminentes contradições entre as classes - as quais estamos denominando: burguesia e proletariado - organiza-se com a função social de reduzir todos os indivíduos à cidadania $^{8}$, pois enquanto cidadãos todos são tratados sob a égide da igualdade, ocultando a desigualdade proveniente da exploração do trabalho justificada pela acumulação do capital. Por conseguinte, a criação do Estado Moderno pela classe burguesa tem como propósito defender os interesses da

${ }^{8}$ Karl Marx na obra Manuscritos econômicos- filosóficos (2010). 
mesma a favor da manutenção da propriedade privada, organizando o poder político a favor de seus interesses.

Contribuindo com tal discussão, Mészáros(2015) evidencia que

[...] as determinações materiais diretas da ordem reprodutiva do capital estão totalmente complementadas pela abrangente estrutura política de comando das formações estatais do capital constituindose, assim, a realidade estruturante interligada e enredada, e o círculo vicioso prático, do sistema do capital como um todo (MÉSZÁROS, 2015, p.87).

Por conseguinte, subsidiados pelo autor acima citado consideramos 0 Estado enquanto constituição e constituinte da realidade social sob a égide do sistema do capital. Assim, o Estado, à medida que se estabelece a partir da realidade vigente e das relações postas, ao se apropriar da sociabilidade humana, também se estabelece, se organiza e incide sobre as relações sociais a partir de sua lógica estruturante, a lógica econômica capitalista de conservação da propriedade privada.

Fundamentados em Mészáros (2012) compreendemos, então, que Estado garante a uma pequena parcela da população o controle político, e, com ele o poder sobre os meios técnicos informacionais e, portanto econômicos, resultando em um processo de manipulação e alienação dos seres humanos. Destarte, o capitalismo de posse das articulações políticas de Estado, produz a ideologia dominante e conduz a racionalidade que prevê a lucratividade em todas as cadeias de seu processo produtivo.

No processo de concretização da propriedade privada, a classe burguesa arraiga seu poder econômico concomitante com as instâncias sociais que até então detinham o poder, ou seja, a nobreza e o clero; e é nesse período histórico, caracterizado pelo limiar entre o medievo e os primeiros passos da modernidade no período renascentista, que observamos uma mudança na forma de compreensão do mundo, influenciada pela ascensão da classe burguesa.

Exaltamos que nesse momento histórico a nobreza encara a necessidade de expandir seus territórios, desbravando os oceanos à procura de novas terras. Porquanto, para que pudessem despender dos recursos financeiros necessários a toda essa jornada foi necessária uma parcela 
significativa de investimentos, os quais são captados pela conciliação com a classe burguesa. Logo, "à medida que a nobreza e o clero vão ficando mais dependentes da classe burguesa para financiar seu estilo de vida e sua política, cresce também o poder que as trocas comerciais vão desempenhando no modo como as pessoas produziam sua existência." (PEDRUZZI, 2015, p. $62)$.

Nesse processo histórico, o Estado sob a égide do capital, rege o sistema jurídico-legal, tendo como incumbência garantir formalmente os direitos dos indivíduos quanto à vida, à liberdade, à igualdade e à segurança, desde que não ultrapassem os limites que comprometem a acumulação da riqueza pela classe dominante. Todavia, na totalidade da sociedade capitalista, 0 trabalho humano é realizado como atividade estranhada, como exploração da força de trabalho dos homens entre si.

Diante disso, mesmo que o princípio governante fundamental da nova sociedade seja o econômico, ele não é cindido da estrutura política na qual se realiza (MARX, 2010). Corroborando com a afirmativa, sustentamos que o sistema jurídico-legal é o protótipo criado pela burguesia para que se generalize e confira à sua classe fundadora a dominação política da totalidade da sociedade.

Essa dialética explica-se pelas determinações econômicas, sociais e
políticas da propriedade privada dos meios de produção, graças a
qual a burguesia se torna, há um tempo, a classe possuidora mais
poderosa e mais hipócrita da história das civilizações fundadas na
estratificação social. Ela proclama uma utopia, a do seu período de
ascensão (efetivamente revolucionária), e pratica uma ideologia de
mistificação sistemática nas relações entre meios e fins (a de seu
período de consolidação), indispensáveis para que ela pudesse ser
modernizadora, em um nível, e conservadora em outro
(FERNANDES, 2006, p. 364).

Reiterando as análises de Florestan Fernandes (2006), no quadro das revoluções ou das situações revolucionárias, de tomada do poder ou efetivação política de uma legislação que tivesse como possibilidade favorecer a classe operária, todas as lutas foram vencidas pela classe conservadora. Contudo, esse não é um privilégio do padrão histórico de controle, mas sim o produto do processo de descolonização, pelo qual parte significativa do país ficou excluída da organização e institucionalização dos direitos civis e políticos. 
Não obstante, compreendemos que o modelo econômico vigente de segregação do homem da natureza natural, de adensamento jurídico de políticas que fragmentam o conhecimento e desarticulam o homem da totalidade do seu trabalho tem como racionalidade a lucratividade em todas as cadeias de seu processo produtivo (CABRERA, 2016).

Diante desse constructo histórico, entendendo o processo pelo qual se faz concreto o sistema capitalista, assegurado por sua instituição política basilar: o Estado burguês,podemos compreender que nessa rede de interesses não há espaço para medidas que previnam a poluição ambiental, para estratégias que visem à diminuição do consumo ou reaproveitamento de matéria prima, nem mesmo para desaceleração do processo produtivo o que normalmente favorece 0 não desperdício de insumos. Para tanto, a racionalidade capitalista de mercado não abre brechas em seus cálculos para a contraditória racionalidade ecológica, a qual considera a temporalidade dos ciclos naturais e a lenta possibilidade de restauração dos recursos da natureza (FOLADORI, 2001).

Para que possamos refletir sobre as relações do capital asseguradas pelo Estado elencamos como exemplo as Políticas verdes, as quais se concentram no bojo das práticas de consumo e são o reflexo ideológico da lógica econômica sob o poder da classe burguesa.

Compreensivelmente, a ideologia dominante do Estado, a qual se concretiza em politicas públicas que viabilizam a produção descontrolado da indústria, tem uma grande vantagem na determinação do que pode ser considerado um critério legitimo da avaliação do conflito, já que controla efetivamente as instituições culturais e políticas da sociedade (MÉSZSÁROS, 2012). Assim, podendo usar descaradamente a linguagem da produção irracional, pois o risco de ser publicamente desmascarada é pequeno, tanto devido àrelação do poder político existente, quanto devido ao sistema de dois pesos e duas medidas aplicadas às questões que estão nas mãos dos defensores da manutenção da ordem estabelecida. 


\section{A CRISE AMBIENTAL E A EDUCAÇÃO AMBIENTAL ENQUANTO POSSIBILIDADE DE RESISTÊNCIA.}

Mediante a conjuntura histórica discutida até então, afirmamos que inseridos em uma Crise Ambiental sem precedentes, engendrada pelas relações de segregação do ser humano com a natureza e subsidiada pelo modo de produção capitalista. Isto é, concebemos a Crise Ambiental vigente enquanto uma Crise Estrutural do Capital (MÉSZÁROS, 2011), a qual se alastra por todos os setores sociais afetando diretamente as condições da vida na terra, usando como instrumento a hegemonia burguesa, legitimada por uma consciência social para manutenção da ordem estabelecida, uma consciência ideológica, e não a pauta da redução do consumo, conforme é disseminado pelo ações do capital por meioda indústria.

Subvencionados por essa concepção - que designa a Crise Ambiental como Crise Estrutural do Capital (MĖSZÀROS, 2011),consideramos a Crise Ambiental pautada nos moldes de produção e consumo e em uma ordem estabelecida pelos países melhor alocados no ranking econômico, industrial, cientifico e tecnólogo. Tal lógica tem seu fundamento na propriedade privada e no lucro, ou seja, na acumulação ilimitada do capital, no uso desmedido de recursos naturais e na destruição acelerada da natureza natural.

Para tanto, a lógica que rege o capitalismo e, em consequência dele, a Crise Ambiental atualmente instaurada, é também fundada na manutenção e no agravamento das desigualdades e das injustiças sociais. Como exemplo disso, podemos citar o caso de consumo de energia dos Estados Unidos, observando-se que, se toda a população do mundo consumisse energia em escala igual aos EUA, em 19 dias nós teríamos esgotado todas as fontes petrolíferas, das quais se têm conhecimento, no mundo (LEHER, 2011).

Estamos em um estágio da Crise Ambiental em que a continuidade do "progresso" capitalista fundado na economia de mercado ameaça diretamente a sobrevivência da espécie humana, principalmente no que tange às vertiginosas mudanças climáticas que assolam o contexto global (COGGIOLA, 2004). O acréscimo desmedido das agressões feitas à natureza natural, nos 
leva a acreditar em uma ruptura, próxima, dos sistemas ecológicos, configurando uma atmosfera catastrófica que põe em risco a vida humana na terra.

Referimos-nos, aqui, à crise estrutural do sistema capitalista que se alastra por todos os setores sociais e afeta as bases fundamentais da sobrevivência humana - as relações com a natureza natural - sendo caracterizada como uma crise em todos os sentidos. Conforme enfatiza Mészáros (2011), chegamos aos limites históricos da competência do capital para o controle da sociedade, e, dessa forma, temos como única alternativa encontrar outra forma de reprodução social, de sociabilidade humana, embasada no controle do processo produtivo pelos trabalhadores.

Para tanto, as lutas travadas em prol da reversão ou, minimamente, da estagnação da Crise Ambiental instaurada, tem sua base também fundada nos anseios pela justiça ambiental, a qual, no caso brasileiro, tem combinado a defesa dos direitos a ambientes culturalmente específicos, de comunidades tradicionais situadas na fronteira da ampliação das atividades capitalistas e de mercado; o amparo aos direitos - para uma proteção ambiental equânime contra a segregação sócioterritorial e contra as desigualdades ambientais agenciadas pelo mercado e aprovadas pelo Estado; a defesa dos direitos de acesso igualitário aos recursos ambientais, em desacordo com a concentração das terras férteis, das águas e do solo acautelado nas mãos dos interesses econômicos do mercado (ACSELRAD, 2009).

Nesse sentido, consideramos urgente a elaboração de um projeto contra-hegemônico que zele pela vida na terra e por suas condições mínimas de sobrevivência, questionador da legitimidade da ação política em prol dos imperativos do capital. Almejamos um projeto que intenta preservar os espaços da crítica ambientalista sobre o modelo social em desenvolvimento.

Para tal, afirmamos a Educação Ambiental enquanto proposta centrada nas relações humanas entre si e com a natureza natural, nas condições de existência material da vida na terra em sua totalidade, partindo do princípio de tornarmos evidente que a forma de produção da vida social é consequência 
das relações econômicas vigentes (MARX, 2017). Buscamos uma Educação Ambiental que denuncie as formas de relações humanas pautadas por um sistema sustentado sobre uma base econômica, que coloca a natureza natural como externalidade humana, ou seja, afirmamos uma Educação Ambiental de caráter político e que conceba o homem também como natureza.

Consideramos, portanto, uma Educação Ambiental que possibilite a compreensão da totalidade, que se articula para além de um simples campo do saber. Educação Ambiental enquanto estratégia político-pedagógica para emancipação dos sentidos humanos acerca dos imperativos do capital, o qual engendra em sua essência o fundamento dessa crise de proporções civilizatórias que imergimos (CRUZ, BIGLIARDI e MINASI, 2013).

Alicerçado no referencial marxiano, compreendemos a Educação Ambiental como estratégia que visa à possibilidade de superação do modo de produção vigorante e das formas atuais de sociabilidade humana, para uma sociedade - como nos chama atenção Marx (2012) e, posteriormente, Mészáros (2008) - de igualdade substantiva. Nela, os indivíduos serão reconhecidos na sua individualidade e cada um contribuirá socialmente na medida de suas capacidades e receberá da sociedade ao grau de suas necessidades.

Momento o qual mulheres e homens se sentirão parte da natureza ao passo que se constituem sociais pelo trabalho (MARX, 2010). Sendo, por meio do trabalho que o homem transforma a natureza natural e é no processo de trabalho que se dá sua transformação de ser natural para ser humano social, pois é através da atividade criativa do homem - o trabalho - que acontece no biológico a formação social, ou seja, o desenvolvimento do ser natural para o humano-social.

Desse modo, concebemos que Educação Ambiental, em sua totalidade, é indissociável da perspectiva de classe. Portanto, se faz necessário alertar que a mesma pode servir tanto de instrumento para a manutenção das condições de exploração e subordinação dos trabalhadores pelos proprietários 
dos meios de produção, quanto de alavanca para a necessária transformação histórica da sociedade.

A Educação Ambiental é considerada por nós como possibilidade de nos desvencilharmos do modelo ditatorial do capitalismo desde que atrelada à moção da classe dos trabalhadores, engajados à redefinição do atual molde econômico, ditador das regras civilizatórias. De tal modo, destacamos em consonância com Goergen (2014) que as múltiplas ações da Educação Ambiental são fundamentais e imprescindíveis enquanto estratégia na luta contra o imperialismo capitalista, mas não são pequenas intervenções no montante da cadeia plural de posturas epistêmicas, éticas e econômicas que redefinirão problemas sistêmicos, conjecturados ao modelo de desenvolvimento ramificado nos últimos duzentos ou trezentos anos.

O vigoroso desafio da Educação Ambiental se põe no sentido de trabalhar como parte integrante de um esforço maior que propendeà transformação radical do modo de produção e a reorientação da sociabilidade humana, contribuindo para que o ser humano se reencontre com meio de produção essencial: a natureza natural. Tendo em vista que as intervenções pedagógicas parcelares, tópicas, disciplinares - as quais consideramos como práticas possíveis hoje - que se efetivam nas brechas deixadas pelo metabolismo do capital, só contribuirão para sociedade que almejamos se estiverem articuladas a moção de compreender o mundo em sua totalidade para que possamos interferir nele de forma consciente.

\section{NOSSAS CONSIDERAÇÕES}

Consideramos a partir da análise da obra Grundrisse de Karl Marx, que a relação do ser humano com a terra - a natureza natural - é condição si nequa non de reprodução e manutenção da sociedade constituída por mulheres e homens. Pois, os seres humanos sempre necessitam da relação com a natureza natural seja para se apropriarem dos recursos que ela thes oferta para efetivação do trabalho, seja pela sua base como sede da existência e do trabalho ou pela relação que o homem mantém com o lugar em que vive.

Nesse constructo, compreendemos que as formações que precedem o modo de produção capitalista, em grande parte, tem latente em sua 
constituição o desenvolvimento do modo econômico para o acúmulo da riqueza material, assim, viabilizando a produção do excedente. Bem como, o sentido de propriedade privada como relação imanente a constituição de muitas das diferentes formações sociais, mesmo que em alguns casos o proprietário dos meios de produção e da terra seja também o trabalhador, o qual autosustenta a produção.

Para tanto, destacamos que diferentes modos de produção convergiram para que um pequeno grupo acumulasse riqueza em detrimento do trabalho de outros, assim propiciando a acumulação sistêmica de excedente, gerando o comércio e intensificando as relações entre capital e trabalho.

Dessa forma, podemos compreender que a complexificação entre as relações capital trabalho - fundadas nas ideias de acumulação da riqueza a partir da exploração do trabalho daqueles que não detinham propriedade privada - se atrela a ideia de campo como extensão da cidade, assim contribuindo para que o modo de produção vigente se desenvolvesse a ponto de se configurar em um sistema que domina a pluralidade da economia mundial.

Por conseguinte, concebemos o Estado moderno como um dos agentes da complexificação do sistema capitalista, o qual é constituído e constituinte pela realidade em que nos encontramos sob égide do capital (Mészáros, 2015). De modo que, o Estado incide sobre as relações sociais a partir e sua lógica estruturante: a econômica capitalista de conservação da propriedade privada.

Concebemos, então, o Estado moderno como o instrumento que garante o controle político e dos meios técnico- informacionais à burguesia, resultando em um processo de manipulação e alienação dos seres humanos (Mészáros, 2012). Logo, a classe burguesa ao deter o poder político no cerne do Estado, conduz ideologicamente a racionalidade capitalista, a qual almeja a lucratividade em todas as faces de seu processo produtivo.

Para tanto, consideramos que o modo de produção capitalista contribuiu para a efetivação das relações de segregação do ser humano com natureza natural, articulando por meio do Estado políticas que fragmentam o conhecimento e desarticulam o ser humano da totalidade o objetiva que ele se 
insere e, principalmente da totalidade do seu trabalho, tendo como racionalidade a lucratividade em todas as cadeias de seu processo produtivo.

Assim sendo, a compreensão de mundo enquanto totalidade está no que evidenciamos desde o início desse texto, no significado de articulação das relações e ligações em que se constitui o mundo. Para que a Educação Ambiental cumpra seu papel fundamental, educativo e impulsionador de outra sociabilidade humana, se faz necessário que a Crise Ambiental seja compreendida em sua totalidade.

\section{REFERÊNCIAS}

ACSELRAD, Henri. O que é justiça ambiental. Rio de Janeiro: Garamond,2009.

BRANDÃO, Carlos Rodrigues. O que é educação popular. São Paulo: Brasiliense, 2006.

CABRERA, Darlene Silveira. A objetivação das Diretrizes Curriculares Nacionais para Educação Ambiental na formação de professores: um estudo de caso no Curso de Pedagogia da FURG.2016. 198 f. Dissertação (Mestrado em Educação Ambiental) - Universidade Federal do Rio Grande -FURG, Rio Grande, 2016.

COGGIOLA, Osvaldo. "Ecologia e Marxismo".RevistaMotrivivência. Ano XVI, nํㅡ 22, p. 39-46, Junho de 2004.2 Disponível em: <https://periodicos.ufsc.br/index.php/motrivivencia/article/.../1183/1887>.Acesso em: 13/09/14.

CRUZ, Ricardo Gautério, BIGLIARDI, Rossane Vinhas, MINASI, Luis Fernando. "Crise ambiental e crise do modo de produção: os limites sócio-metabólicos do capital". Revista Eletrônica do Mestrado em Educação Ambiental, abril 2013. Disponível em: <http://www.seer.furg.br/remea/issue/view/408>. Acesso em: 10/03/15

FERNANDES, Florestan. O que é Revolução? In: BOGO, Ademar (org). Teoria da organização política. 1ed. São Paulo: Expressão Popular, 2006.

FOLADORI, Guilhermo. Los Limtes del desarollo sustentable.Salvador: Editora Unicamp, 2001.

GORGEN, Pedro. "A ética e o futuro da humanidade: considerações críticas sobre educação ambiental". Revista Pesquisa em Educação Ambiental, vol. 9, n. 1 - pg. 10-23, 2014. Disponível em: http://www.periodicos.rc.biblioteca.unesp.br/index.php/ pesquisa/search/search. Acesso em: 11/11/15.

LEHER, Roberto. "Desafios para uma educação para além do capital". In: JINKINGS, Ivana e NOBILE, Rodrigues (org.). Mészáros e os desafios do tempo histórico. São Paulo: Boitempo, 2011. 
LENIN, Vladimir llitch. O Estado e a Revolução. São Paulo: Global, 1987.

MARX, Karl \& ENGELS, Friedrich. O manifesto do partido comunista. [trad. de Marcos Aurélio Nogueira e Leandro Konder]. Petrópolis, RJ: Vozes, 2011.

MARX, Karl. Crítica ao Programa de Gota.[trad. Rubens Enderle]. 1.ed.São Paulo: Boitempo, 2012.

Grundrisse: manuscritos econômicos de 1857-1858: esboços da crítica da economia política. [trad. Márcio Duayer e Nélio Schneider]. $1^{\text {a }}$ ed. São Paulo, SP: Boitempo; Rio de Janeiro, RJ: Ed. UFRJ, 2011.

Manuscritos econômico-filosóficos. [trad. Jesus Ranieri]. 1.ed. São Paulo: Boitempo, 2010.

O Capital. Livro 3. [trad. Rubens Enderle]. $1^{\text {a }}$ ed. São Paulo: Boitempo, 2017.

MÉSZÁROS, István. A crise estrutural do Capital. [trad. Francisco Raul Cornejo et al.].2.ed. São Paulo: Boitempo, 2011.

A educação para além do capital. [trad. Isa Tavares]. 2.ed. São Paulo: Boitempo, 2008.

A montanha que devemos conquistar. [trad. Maria Isabel Lagoa]. São Paulo: Boitempo, 2015.

O poder da ideologia. [trad. Magda Lopes e Paulo Cezar Castanheira]. 1.ed., 4.reimp. São Paulo: Boitempo, 2012.

PEDRUZZI, Alana das Neves. A formação em Educação Ambiental na ênfase em Gestão do Patrimônio Socioambiental do Curso de História-bacharelado da Universidade federal do Rio Grande -FURG. 2015. 140 f. Dissertação (Mestrado em Educação Ambiental). Universidade Federal do Rio Grande - FURG, 2015.

SANTOS, Milton. Da totalidade ao lugar. $3^{\mathrm{a}}$ Ed. São Paulo: Editora da Universidade de São Paulo, 2014.

Técnica, Espaço, Tempo: Globalização em meio técnicocientifico- informacional. São Paulo: Editora Hucitec, 1994. 